Gnetales-comprising Gnetum, Welwitschia and Ephedra (Phytomorph., 2, 1, 79; 1952). These plants have long been prominent because of their very curious morphology and diverse habit, and because they appear to occupy a position intermediate between gymnosperms and angiosperms. The evidence now available points to the need for an extensive taxonomic revision. As a result, the three families are separated and raised to ordinate rank. Moreover, it is recognized that the Ephedrales have no phylogenetic relationship to the Welwitschiales and Gnetales. They are, however, closely related to the Cordaitales, both having similar appendicular ovules. Ephedra, in fact, is regarded as a derivative of ancient cordaite-conifer stock.

Papers from the Arcetri Astrophysical Observatory

Publication No. 67 of the Faculty of Mathematical, Physical and Natural Sciences of the University of Florence, entitled "Osservazioni e Memorie dell' Osservatorio Astrofisico di Arcetri" (pp. 141, 1952), consists of eleven papers contributed by seven authors. These papers deal with a variety of subjects : correlation coefficients between areas of sunspots and areas of calcium and bright $H \alpha$-flocculi ; results of the examination of the mean heliographic latitude of sunspots and that of bright flocculi, from which it appears that the former are smaller than the latter; relative photometric intensities of chromospheric flares, measured monochromatically in $H \alpha$ and $K 2 \cdot 3$ lines, on 258 spectroheliograms recorded during 1950 with the solar tower of Arcetri Observatory; study of the eleven-year cycle of solar prominences, without taking into consideration the distinction between those in high and low latitudes, and comparing prominences with filaments, some differences in their behaviour being detected; photometric measurements of the ghosts given by the grating of the Arcetri solar tower; relative intensities of flares and bright flocculi observed in $H_{\alpha}$ light on spectroheliograms taken at Meudon, and a comparison with those taken at Arcetri, etc.

\section{The Night Sky in January}

FUlL moon occurs on Jan. 0d. 05h. 05m., U.T., and also on Jan. 29d. 23h. 44m., and new moon on Jan. $15 \mathrm{~d} .14 \mathrm{~h} .08 \mathrm{~m}$. The following conjunctions with the moon take place: Jan. 9d. 09h., Saturn $8^{\circ}$ N.; Jan. 19d. 0lh., Mars $4^{\circ}$ S. ; Jan. 19d. 0lh., Venus $4^{\circ}$ S. ; Jan. 23d. 02h., Jupiter $7^{\circ} \mathrm{S}$. In addition to these conjunctions with the moon, Venus is in conjunction with Mars on Jan. 18d. 02h., Venus being $0.2^{\circ} \mathrm{N}$. Mercury, a morning star, rises at $6 \mathrm{~h} .50 \mathrm{~m}$. on January 1, but later in the month it draws too close to the sun for favourable observation. Venus, an evening star, sets at $19 \mathrm{~h} .50 \mathrm{~m} ., 20 \mathrm{~h} .30 \mathrm{~m}$. and $21 \mathrm{~h} .10 \mathrm{~m}$. on January 1,15 and 31 , respectively, stellar magnitude averaging -3.9 and the visible portion of the illuminated disk varying between 0.65 and 0.52 . Mars is an evening star, setting about $20 \mathrm{~h}$. $35 \mathrm{~m}$. throughout the month; its stellar magnitude varies between $1 \cdot 2$ and $1 \cdot 3$. Jupiter sets at $3 \mathrm{~h} .10 \mathrm{~m} ., 2 \mathrm{~h} .10 \mathrm{~m}$. and $1 \mathrm{~h} .15 \mathrm{~m}$. at the beginning, middle and end of the month, respectively, its stellar magnitude averaging $-2 \cdot 1$. Saturn, a morning star, rises at $1 \mathrm{~h} .40 \mathrm{~m} ., 0 \mathrm{~h} .45 \mathrm{~m}$. and $23 \mathrm{~h} .45 \mathrm{~m}$. on January 1,15 and 31 , respectively ; its stellar magnitude is about 0.9 , and it lies a little north-east of $\alpha$ Virginis (Spica). There is only one occultation of stars brighter than magnitude 6 in January, namely, $\pi$ Canc., which reappears at $6 \mathrm{~h} .18 \cdot 3 \mathrm{~m}$., assuming that observations are made at Greenwich. A total eclipse of the moon takes place on January 29/30 and is visible in the British Isles. The circumstances of the eclipse are as follows :

$\begin{array}{lrll}\text { Moon enters penumbra } & \text { Jan. 29d. 20h. } 40 \cdot 1 \mathrm{~m} \text {. } \\ \text { Moon enters umbra } & 29 & 21 & 54 \cdot 1 \\ \text { Total eclipse begins } & 29 & 23 & 04 \cdot 6 \\ \text { Middle of eclipse } & 29 & 23 & 47 \cdot 3 \\ \text { Total eclipse ends } & 30 & 00 & 29 \cdot 9 \\ \text { Moon leaves umbra } & 30 & 01 & 40 \cdot 4 \\ \text { Moon leaves penumbra } & 30 & 01 & \mathbf{5 4} \cdot 5\end{array}$

The earth is at perihelion on January 2.

\section{Announcements}

Prof. J. F. BAKER, professor of mechanical sciences and head of the Department of Engineering, University of Cambridge, has been awarded the Ewing Gold Medal of the Institution of Civil Engineors, in recogmition of his contributions to engineering research.

IN reply to a question in the House of Commons, the Minister of Works stated that the planning of the Government Science Centre has had to be deferred in view of the need for economy. When the economic situation improves, it is hoped to lease a site on the South Bank immediately below Waterloo Bridge.

THE annual exhibition of the Television Society, dealing with television engineering or production or with the production of television programmes, will be held during January 23-24, 1953, at 155 Charing Cross Road, London, W.C.2, by invitation of the Edison Swan Electric Co., Ltd. The exhibition will be open as follows: January 23, 6-9.30 p.m., members and friends ; January 24, 10.30 a.m.-6 p.m., members. Public admission is by invitation card, obtainable from members of the Society, patron members or from the lecture secretary, G. T. Clack, 43 Mandeville House, Worsopp Drive, London, S.W.4.

A symposium on anticholinesterases, arranged jointly by the British Pharmacological Society and the Fine Chemicals Group of the Society of Chemical Industry, will be held during March 27-28, 1953, at the Wellcome Research Institution, Euston Road, London, N.W.1. The symposium will be in four sections : chemical features which confer inhibition; mode of action in vitro; mode of action in vivo (acute effects); mode of action in vivo (chronic effects). Further information can be obtained from the honorary secretary of the British Pharmacological Society, Mr. George Brownlee, at the Physiology Department, King's College, Strand, London, W.C.2.

AN International Congress on Electroacoustics will be held in the Netherlands during June 16-24, 1953, under the auspices of the International Commission on Acoustics of the International Union of Pure and Applied Physics. Lectures and invited short contributions will be read covering the following sections: (1) sound recording, (2) publicaddress systems, (3) acoustic measurements, (4) hearing-aids and audiometers, (5) electroacousties in ultrasonics, and (6) electroacoustics applied to musical instruments. These will be followed by a symposium on the sound insulation of lightweight structures. Further details can be obtained from the secretary, Dr. P. A. de Lange, Mijnbouwplein 11, Delft.

The lectures delivered at the vacation school on the "Insulation of Electrical Equipment" held at the Imperial College, London, in September (see Nature, Dec. 13, p. 1006) are being published in book form by Chapman and Hall, Ltd., 37 Essex Street, London, W.C.2, under the editorship of Prof. Willis Jackson. 